\title{
$\mathrm{LED}$ 용 $(\mathrm{Sr}, \mathrm{Ba})_{2} \mathrm{Ga}_{2} \mathrm{SiO}_{7}: \mathrm{Eu}^{2+}$ 녹색 형광체의 합섬 및 발광특성
}

\author{
이승재 · 박정규* - 연정호 - 김창해 \\ 한국화학연구원 화학소재연구부 형광물질연구팀
}

(2005. 11.25 접수)

\section{Synthesis and Luminescent Characteristics of $\left(\mathrm{Sr}, \mathrm{Ba}_{2}\right)_{\mathrm{Ga}_{2}} \mathrm{SiO}_{7}: \mathrm{Eu}^{2+}$ Green Phosphor for LEDs}

\author{
Seung Jae Lee, Joung Kyu Park*, Jeong Ho Yeon, and Chang Hae Kim

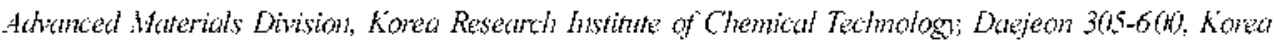 \\ (Received November 25. 2005)
}

요 약. $\mathrm{Eu}^{2+}$ 를 활섬제로 한(S.Ba) $\mathrm{Ga}_{2} \mathrm{SiO}_{7}$ 녹색 형광체를 일반적인 고상 반응으로 합성하였고. 그 합성된 형 광체의 광발광 특성을 연구하였다. 형광체 제조 시, 마노유발에서 보다 효과적인 혼합을 위하여 아세톤을 사 용하여 혼합하였다. 또한 $25 \% \mathrm{H}_{2} / 7 \% \% \mathrm{~N}:$ 의 혼합기체를 이용한 환원조건에서 단순한 공정으로 형광체를 합성하 였다. 이 혐광체는 $405 \mathrm{~nm}$ 의 여기 파장하에서 효율적으로 발광되는 녹색 밴드 $(513 \mathrm{~nm})$ 를 갖고 있기 때문에 백색 LEDiLight Emitting Diote)램프에 응홍할 수 있나.

주제어: ( $\mathrm{St}, \mathrm{Bar}_{2} \mathrm{Ga}_{2} \mathrm{SiO}_{7}: \mathrm{Eu} \mathbf{u}^{-}$, LED(Light Emitting Diode), 광발광, 혐광체

\begin{abstract}
In this report, Europium doped strontium barium gallium silicate ( $\left.(\mathrm{Sr} ; \mathrm{Ba})_{2} \mathrm{Ga}_{2} \mathrm{SiO}_{;}: \mathrm{Eu}^{2-}\right)$ phosphor has been synthesized by conventional solid-state method and investigated luminescent characteristic. Appropriate proportions of the raw materials were mixed in an agate mortar i ith acetone to obtain starting mixtures. Also, this phosphor was prepared by simple process under the reduction atmosphere $\left(25 \% \% \mathrm{H}_{2} / 75 \% \% \mathrm{~N}\right)$. This phosphor can be applicated to the green phosphor for white LED because it has green emission band ( $513 \mathrm{~nm}$ ), which emits efficiently under the $405 \mathrm{~nm}$ excitation energy.
\end{abstract}

Keywords: (Sr,Ba), $\mathrm{Ga}_{2} \mathrm{SiO}_{7}: \mathrm{Eu}^{2+}, \mathrm{LED}(\mathrm{Light}$ Emitting Diode), Photoluminescence. Phosphor

\section{서 론}

현 재까지 조명시장의 대부분을 차지하고 있는 빽열 전등과 형광등을 대체할 조명수단으로 부각되고 있 는 것으로. White LED(Light Emitting Diode)가 있다. LED란 P-N 접합 반도체로 된 다이오드의 일좀으로 발광효율이 $100 \%$ 에 가까욱며. 전자의 이동속도가 높 고 고은으로도 동작이 가능하며, 고속 및 고 전력 전 자소자에 널리 사용된다. 이 $\mathrm{LED}$ 는 반도체로 이루어 져 있기 때문에 전구 등의 다른 열변한 발광소자에 비해 안정적이고 신뢰성이 있으며, 그 수명도 연속통
전 상태에서 10 반 시간 이상으로 길다. 또한. 전력소 비가 기쫀 전구의 약 $1 / 12$ 에 불과하고. 수명은 전구의 100 배 이상인 반면, 신호 반응속도는 기존전구보다 1000 배 이상 빠른 게 특징이다. 보톰의 반도체소자와 마찬가지로 $\mathrm{LED}$ 소자 그 자체는 칩(chip)이라 불리고, 그 코기는 보통 수백 $\mu \mathrm{m}$ 로 매욱 각나. $\mathrm{LED}$ 의 발광 색은 백열전구 능으로부터 발광하는 백색 광 둥 폭 넓 은 빚과는 달러 단색에 가깜다. 즉, 발광스퐸트럼이 좁은 특징을 가지고 있다. 반도체 채료의 선택에 따 라 적색, 오렌지색, 황잭, 녹잭 등 다양한 파징의 빛 을 내는 다이오드가 생산된다.' 
백색 I.1:D는 1993년 일본의 나카고-라의 $470 \mathrm{~nm}$ 의 칭색 칩의 빌명으로 인해 적. 녹. 청색의 산색 칩으로 표시소자의 역할만 해욌던 LED가 Display에 적용될 가능성이 대두되었다.' 가시광 영멱에서 우수한 발광 륵성을 내는 YAGCC을 제외하면 일반석.으로 알려진 형광체는 $380 \mathrm{~mm}$ 이상의 징파징 자외선 하에서 낮은 회느를른 나타넨나. 또한 청색 발광을 하는 (idN에 YAG:Ce을 도포하근 경웅. 색숙도 년에시 순수한 백 색이 아닌 침색 빛이 강한 벼색 발광을 하게 된다. 따 라서 장파잠 자외선을 여기원으로 하는 장파장 자외 선 IIV chip 위에 척생. 그새새, 청새 박퐝을 하는 형광

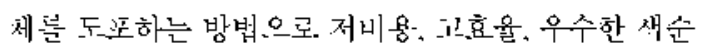
도를 가지는 벡색 I.III)를 제쏘하는 것이 가능하나. 이 러한 접에서 I.IID)와 형광체를 결합시켜 새로운 형배 의 LED률 게발하기 위해시는 고효윤 발광의 자외선 $\mathrm{LED}$ 개발과 더불어 이에 도포하기에 적절하고 발광 강도가 우수한 형광체의 개발이 매우 충요하다.

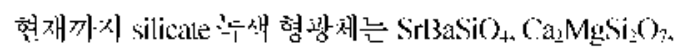

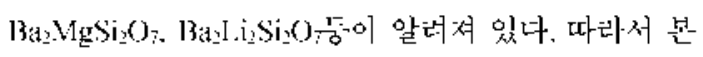
연-가에서는 벡식 IIII) 구현을 위해 장과장 $\mathrm{CV}$ 에서 높 윽- 발광득싱을 가지는 적색. 녹색. 칭색 형광체 증에시 ( $\mathrm{Sr} \cdot \mathrm{Ba})_{2} \mathrm{Ga}_{2} \mathrm{SiO}_{7}: \mathrm{Eu}^{3+}$ 녹색 형광체를 개발하고자 하였다.

\section{실험방법}

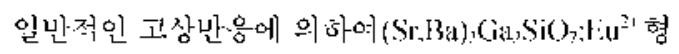
광체를 합심하였고. 식헙과정은- $F$ g 내었다. 춘발문질로 고순도 사의 $\mathrm{SrO}_{3-\mathrm{BxO}} \mathrm{SiO}_{2}(4 \mu \mathrm{m})$. $\mathrm{Gaa}_{2} \mathrm{O}_{3} . \mathrm{Eu}_{2} \mathrm{O}_{3}$ 를 사용하혀 시로가 힐싱의 조성이 회도 록 각각을 칭량한 다음. 마노유막(Morlar)에서 보다 효과식인 혼합 및 분쇄는 위하어 아세톤을 용내로. 하 여 혼합하었다. 남아있는 수분이나 아세본을 제거하 기 위해서 $80^{\circ} \mathrm{C}$ 에서 1시간 동안 건소시켰다. 3 가 상 태의 $\mathrm{Eu}$ 룰 2 가의 $\mathrm{Eu}$ 으로 환원시키기 위해시 $25 \% \mathrm{H}_{2}$ $75 \% \mathrm{~N}_{2}$ 분위기하에서 관형 노(tube turnace)에서 멸처 리하었다. 이때 최적의 합성 조건을 찾고사 소섬 온도. $\mathrm{Ba}$ 의 농도. $\mathrm{Bu}$ 의 농도 등을 변화시켜 실험을 진행하 었다. 열체러한 시료의 결정성을 화인하기 위해서 Rikakแ사의 DMAX-33 X-신 회질 분석기로 촉정하였 으녀. 헝광체의 발광특성은 빛 빌광 $\mathrm{PL}$ 및 여기 스 페는럼은 제는 방신롐프(Xenon Flash Lamp)를 내상 한 Perkin Elmer LS 50 spectrometer를 사용하여 족싱

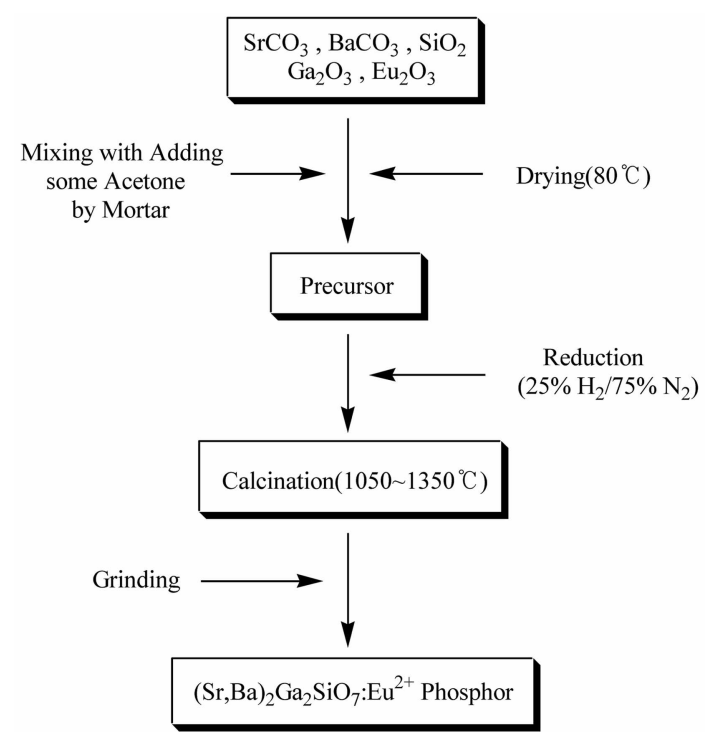

Fig. 1. Flow chat of experimental procedure.

하었다. 또한 II (이 사의 JSM-6360 SEM(Scanning Iilectron Microscopy)으로 입자 코기 및 모양을 관찰하였나.

\section{결과 및 고찰}

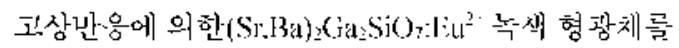

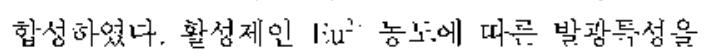
Fig. 2에시와 같이 비교해 본 견과. 0.04 mol의 $\mathrm{Eu}$ 가 도핑 되었을 때 가장 높은- 빌광-세기를 나타내있나. $\mathrm{Eu}^{2+}$

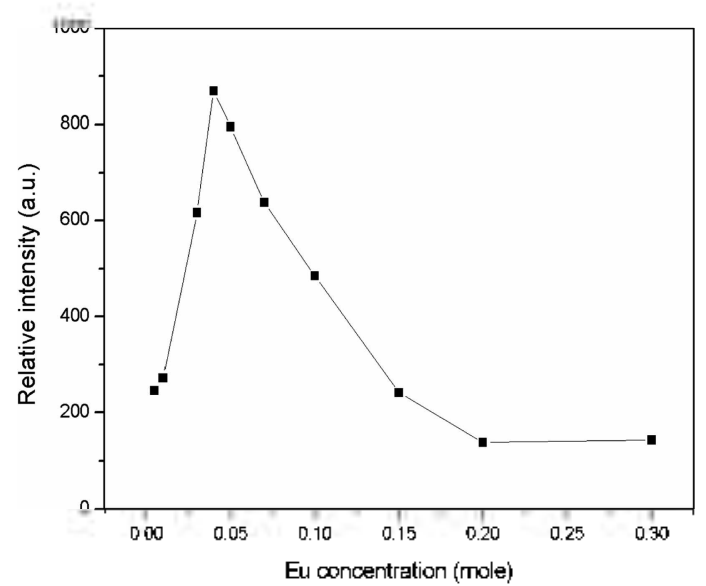

Fig. 2. PI cmission intensities of ( $\mathrm{Sr}, \mathrm{Ba})_{2} \mathrm{Ga}_{2} \mathrm{SiO}-\mathrm{F} \cdot \mathrm{u}^{2-}$ phosphors with respect to Feu- contents $\left(\lambda_{\mathrm{s}}=405 \mathrm{~nm}\right)$. 


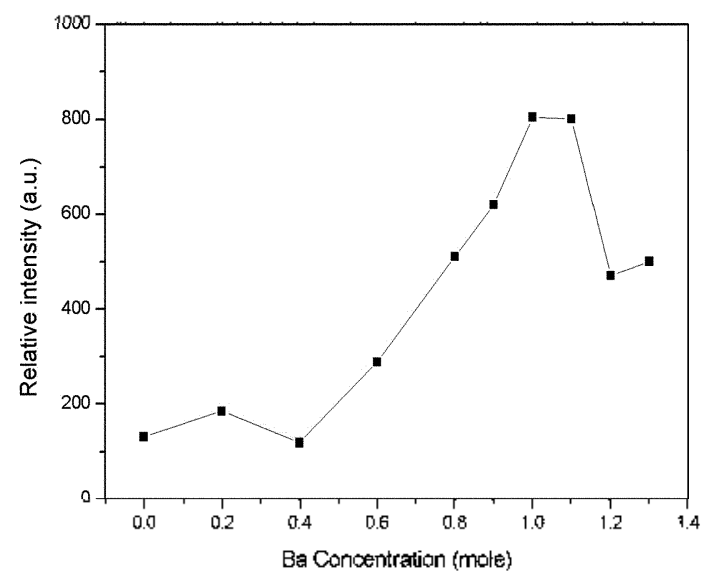

Fig. 3. PL emission intensities of ( $\left.\mathrm{Sr}_{3} \mathrm{Bi}\right)_{2}(\mathrm{Cal}-\mathrm{SiO})-\mathrm{Cu}^{2+}$ phosphors with respect to Ba contents $\left(\lambda_{\mathrm{w}}-405 \mathrm{~mm}\right)$.

의 농도가 $0.04 \mathrm{~mol}$ 이상이 되면 1ㅏㄱ퐝세기가 젂차 감

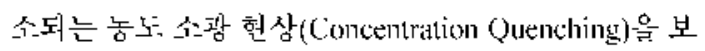

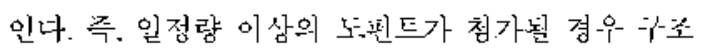
적인 불규일싱(Structural Heterogencity)과 화학저 북 잡성(Chemical Complexity)이 증기하여 발광세기가 갑 소하세된다. ${ }^{3+1}$ 특히 $\mathrm{Eu}^{3+}$ 이온의 겅우 발광 상태 및 에 너시 전이에 대한 임계거러가 5 A인 점을 감안할 때. 홯성 이은의 농도가 긍가할수록 이웃 산슨이은에 근 접하고 산소의 빈자리가 혐성되어 I닐 이온파 산소 이옷의 거더가 짦아저세 이웃-하는 환성이온늘 사이 에 전기 쌍강자 상호작용을 윤발하고. 이것이 이옷대 를 헝섬하여 비발광 충심이나 긱리로 삭용된다고 불 수 있다.

$\mathrm{Fu}^{2}$ 의 양을 $0.04 \mathrm{~m}$ 이로. 드정하였을 때 $\mathrm{Ba}$ 의 양에 따른 혐강체의 박강세기를 비표해꼰 결과 $/ \mathrm{ig}$. 3에서 와 간이 $\mathrm{S} r$ 나 13 이 $1: 1$ 일 때가 가장 높은 발광세기를나타내었다. $\mathrm{Ba}^{2+}$ 이 $\mathrm{Sr}^{2}$ 보다 이온반경이 더 크기 때 눅에 $\mathrm{Sr}^{3+}$ 사리에 $\mathrm{Ba}^{2+}$ 이 치환되닌 신체 구조에서 $\mathrm{Sr}^{2}$ 과 $\mathrm{O}^{\prime}$-사이의 기리보다 $\mathrm{Ba}^{3}$ 자 $\mathrm{O}^{\prime-}$ 사이의 기러가 더 길 이진다. 결과석으로. 구조식인 뒤툰립이 날생하.j! $\mathrm{Eu}^{21}$ 가 높ㅍㅇㅇ될 수 있는 공간이 많아지고 따라서 발광강그 가 증가한나. 난면 13:0이 1:I 이상으ㄹㅗㅗ 치환되면 뒤틀 릮이 오히려 작아져 상대적으로 $\mathrm{Eu}^{2+}$ 가 도푕횔 홍간 이 출어 늘게 되어 발광강도는 감소할 것으로 생 각된다.

Fig. 4는 다양한 소성온도에 따른 ( $\mathrm{Sr} \cdot \mathrm{Ba}_{2} \mathrm{Ga}_{2} \mathrm{SiO}_{7}: \mathrm{Eu}^{2+}$

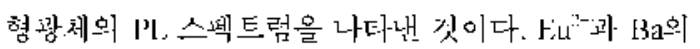

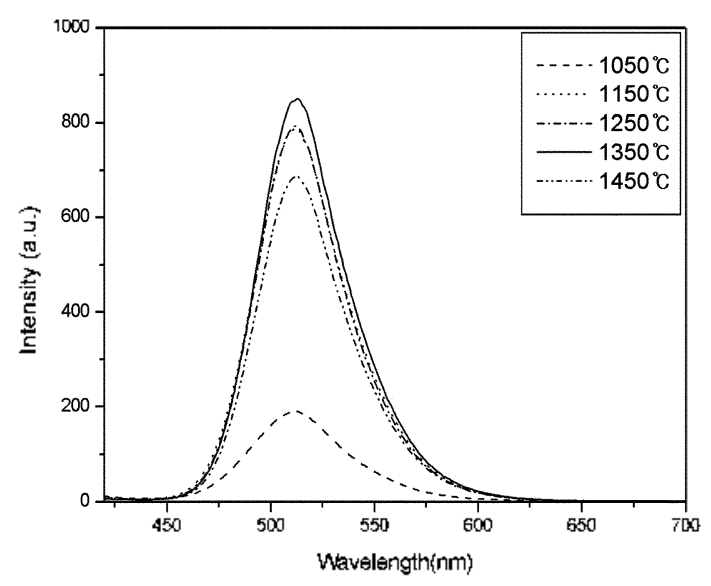

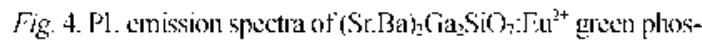
phors as a function of firing temperature.

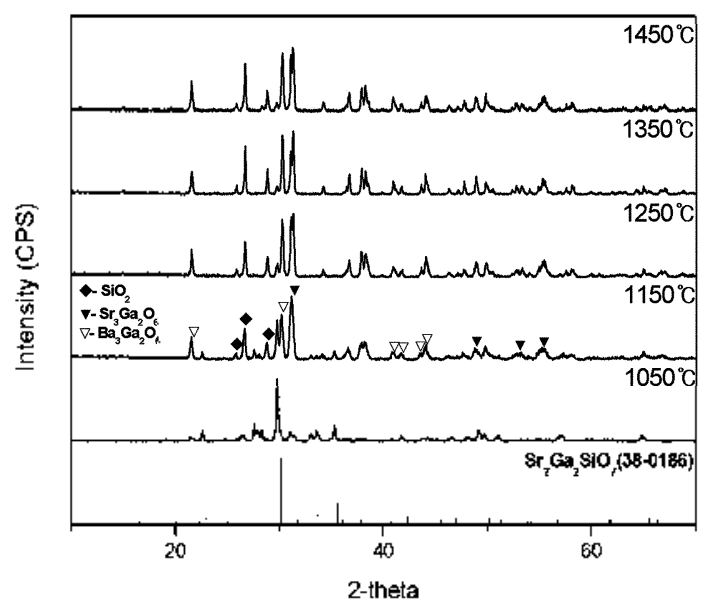

Fig. 5. X-ray diffaction patterts of (Sr.BanGiasion:Eu' and

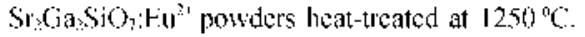

능도를 각각 $0.04 \mathrm{~mol}$ 과 $1 \mathrm{~mol}$ 로 고정하여 $1050-1450^{\circ 1} \mathrm{C}$ 의 온도범위에서 3시간 명안 열처리하여 합성하였다. $1050^{\circ} \mathrm{C}$ 에서 서서히 상이 형성되기 시작해 온-도가 증 가합에 따라 접차 발광홍윤은 증내뎐나. 그림에서 볼 수 있듯이 1350 "(에서 가장 높은 발광 세기를 나타냈나. 옵도에 따른 ( $\mathrm{Sr} \cdot \mathrm{Ba}), \mathrm{Ga} \mathrm{SiO}_{7}: \mathrm{Eu}^{2+}$ 형 광-刘의 X-선 회 전빈셔 견과른 Fig. 5 에 나타내었다. $1050^{\circ} \mathrm{C}$ 에서는: $\mathrm{Sr}_{2} \mathrm{Ga}_{2} \mathrm{SiO}_{7}$ 의 조성을 가지지민. 온도가 증가 할수록 $\mathrm{SiO}_{2} . \mathrm{Sr}_{3} \mathrm{Ga}_{2} \mathrm{O}_{\mathrm{t}} \mathrm{l3a}_{3} \mathrm{Ga}_{2} \mathrm{O}_{0}$ 의 혼합상.으로. 존재하드르 있다. 일반식인 고상반응에 의혜 합성힌 형광체의 낙퐝 


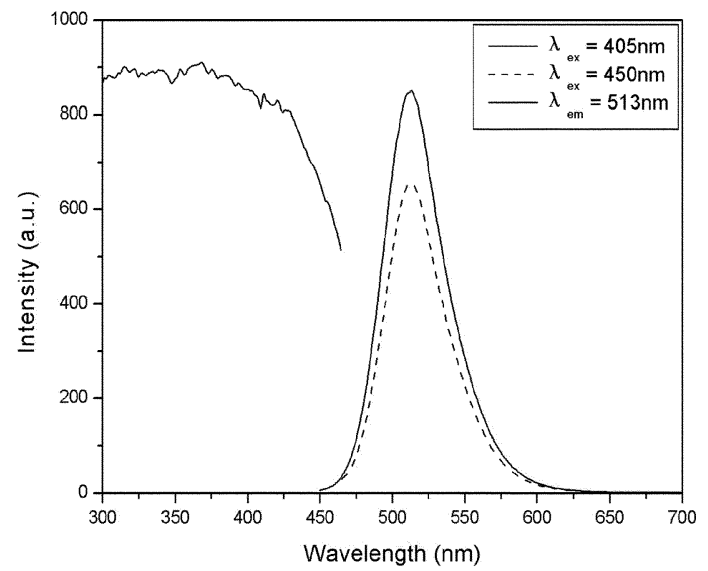

Fig. 6. Typical P' I. excitation spectra (lett slide) and cmission spectra (right slide) of ( $\mathrm{Sr} \cdot \mathrm{Ba})_{2} \mathrm{Ca}_{2} \mathrm{SiO}_{7}: \mathrm{Ku}^{2+}$ phosphors prepared by solid-state reaction.

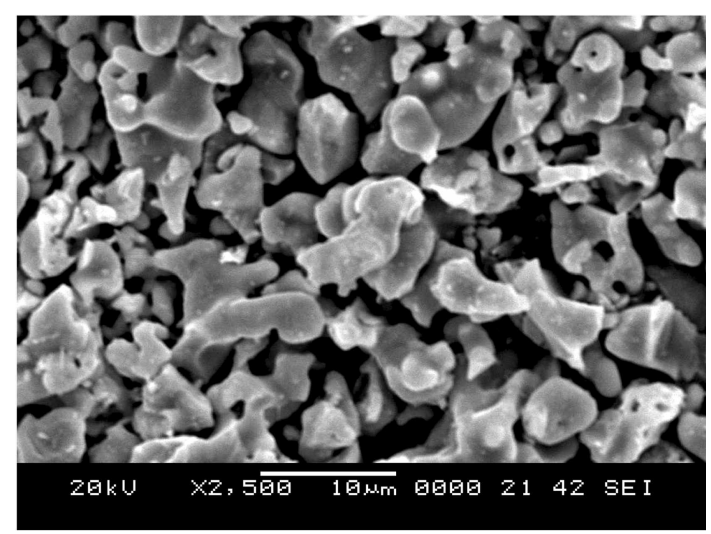

Fig. 7. St.M photographs of \& $\mathrm{Sr}$ Bay GasiO: Hu" phosphors prepared by solid-state reaction.

스펙트럮을 $\mathrm{Fg}$. 6에 나타대었다. 발광 스펙트럼의 경

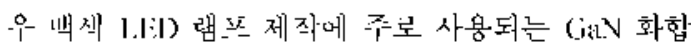
물 반도체룰 사용하기 때문에 $405 \mathrm{~nm}$ 와 $450 \mathrm{~nm}$ 의 여 기 파삼 하에서 흑심하였다. 받광 스펙브럽을 살펴보. 면 $405 \mathrm{~nm}$ 가 $450 \mathrm{~nm}$ 여기 파상하의 값보다 큰 값을

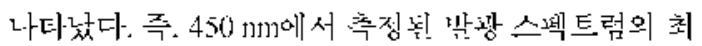
대 세기는 $405 \mathrm{~m}$ m에서 촉정 뎐 것의 $72 \%$ 의 호-울난을 보여준다. 각가의 중심피 $\equiv=1$ 는 $513 \mathrm{~nm}\left(\lambda_{\mathrm{si}}=4(05 \mathrm{~nm})\right.$ 퐈 $512 \mathrm{~nm}\left(\lambda_{\mathrm{m}}=450 \mathrm{~nm}\right)$ 로 거의 비슷학 값을 보여순나. 따 라서. ( $\mathrm{Sr}: \mathrm{Ba}_{2} \mathrm{Cat}_{2} \mathrm{SiO}_{7}: \mathrm{Eu}^{i+}$ 은- $513 \mathrm{~nm}$ 부근에시 높은발광강도를 보혀 배색을 구현할 수 있는헝황체 충 눗새 형뢍체로의 응용이 기능하다.

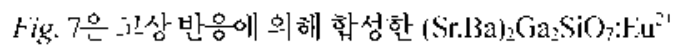

낙색 형광체의 입자형상 밫 코기롤 주사젖자현미경 으로 관찰한 견과률 나타낸 것이다. LED용 형광체의 검우 입차크기가 발광효율 및 LED 제조 공싱상에 큰 영향을 미친다. 크기가 네누 크게 되면 칩 위에 도포 될 떼 균일하게 도포되기 어려우며 너무 작으면 형광 체 자체의 받광흐율이 떨이진다. 따라서 혐광체가 I,E.D) 칩 위에 15 포됨에 있어 적당한 코기는 $10-20 \mu \mathrm{m}$ 내 외라 할 수 있다. ${ }^{\times}$그닐에서 보늣이 세조된 형광체 입 자의 크기가 $515 \mu \mathrm{m}$ 정도로 백색 LED에 응용할 수 있는= 적당한 크기인을 확인 할 수 있었다.

\section{결 론}

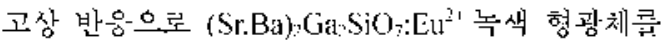
합성한 결과. $\mathrm{Sr}$ 과 $\mathrm{Ba}$ 의 걍도비가 I:1일 때. 그러고 환 성제인 $\mathrm{Eu}$ 의 농도가 $0.04 \mathrm{~mol}$ 에서 가상 늘은 발광세 기를 나타네었다. X-선 회절 분석결과 예상했던 $\mathrm{Sr}_{2} \mathrm{Ga}_{2} \mathrm{SiO}$, 회설패턴이 아닌 전혀 새로-운 회설패턴을 나타내었다. $513 \mathrm{~nm}$ 브근에서 높은 발광강근(intensity

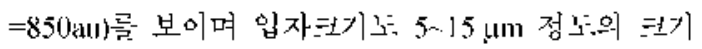
룰 가지브로 백색을 구현할 수 있는 헝광체 종 녹색 힝광체로 응용될 수 있는 가능성을 확인 할 수 있었다.

\section{인 욤 문 헌}

1. Shoichi, M.. I.ight Finitting Diode Display. Flectrontic Displan: 1988. 199-249.

2. Nakamura S.: Fasol. G. The blue I aser Diode: GaN based light enitters and l asers. Sprifger, Berfir, 1997. 343.

3. Soln. S. J.: White-l ight Develepment Technology Trend Bull. of the KIFEME. 2001. If(II). 20-24

4. I leng. C. II. The L.attest Researeh Trend of White-Fmitting L.FDs for Semiconductor Illumination. Bufl. of the KIEEWH. 2001. $H+(11) .25-31$.

5. Kim. Il. W. Yco. l. S. Optical Design of RGBB L.E.D Cluster Lumps. $J$. of the KHEE. 2001. 129-132.

6. Laverenz. HI. W. An introduction to luminescent of solids. Dover Sew rork, 1968. 333-337.

7. Dexter. D. L.. A Theory of Sensilized Luminescence in Solids. J. Chen. Ptns. 1953. 21. 836-850.

8. 긲재녕. 김경납. 박정가. 심창해. 잠호겸. “드상볍을 이용

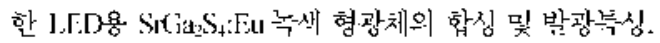

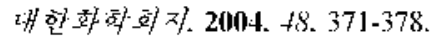

